\title{
ИНСТИТУЦИОНАЛЬНОЕ ДОВЕРИЕ К БАНКАМ КАК УСЛОВИЕ РЕАЛИЗАЦИИ ИХ ЭКОНОМИЧЕСКИХ ИНТЕРЕСОВ
}

\author{
(c) 2019 Мишин Алексей Юрьевич \\ Руководитель подкомитета по защите прав кредиторов \\ Комитета по финансовым услугам Деловой России \\ Общероссийская общественная организация «Деловая Россия» \\ 119121, Москва, 2-й Вражский переулок, д. 1 \\ E-mail: Alink2501@gmail.com
}

В статье рассматривается роль доверия как основного условия формирования и реализации экономических интересов коммерческих банков. Доказано, что рост доверия к банковскому институту обусловливает повышение эффективности его функционирования, что обеспечивает наиболее полное удовлетворение потребностей макроэкономических субъектов. Обоснованы рекомендации по формированию эндогенных институтов, формирующих основу институциональной среды финансового сектора и способствующих реализации институциональных интересов коммерческих банков.

Ключевые слова: институт, доверие, коммерческий банк, институциональная среда, экзогенный институт, эндогенный институт, институциональный интерес, экономический интерес.

В последние ряд лет в научном сообществе все чаще возникает дискуссия относительно роли феномена доверия в развитии социально-экономической системы в целом, и, в частности, ее финансового сегмента. Наиболее остро вопросы доверия стали обсуждаться после кризисных событий 2014 года, повлекших беспрецедентное падение уровня доверия к финансовым институтам. Как правило, снижение институционального доверия выражается в массовом оттоке сбережений населения из кредитных организаций, что еще больше дестабилизирует банковский сектор, вызывая рост рисков и снижение конкурентоспособности коммерческих банков. У представителей научного сообщества не возникает сомнений относительно роли институциональных факторов в развитии экономики, в том числе ее финансового сектора. Функционирование институциональной системы обеспечивается комплексов институтов формального и неформального характера [1], которые существенным образом различаются как механизмом своего возникновения, так и процессом воспроизводства во времени и пространстве. Если говорить о формальных правилах и нормах, то следует отметить, что они жестко фиксированы, имеют публичный характер и обладают вполне четким механизмом принуждения. Естественно, что функционирование формальных институтов благоприятно сказывается на развитии банковского сектора, так как уменьшает неопределенность, риски и размер трансакционных издержек. Категория формальных институтов достаточно хорошо изучена представителями институционализма, так, например, австрийская школа институционализма называет их экзогенными, так как полагает, что они «сконструированы и установлены сверху» [2]. Как правило, это либо внешние организации, такие как МВФ, Всемирный банк, ЕС и ряд других, либо институты национального правительства, к которым можно отнести, например, Банк России. В первом случае австрийская школа институционализма полагает, что это введенные извне экзогенные институты, в то время как второй случай связан с функционированием так называемых введенные изнутри институтов.

В отличие от формальных (экзогенных) институтов, неформальные нормы - это ментальные стереотипы, обычаи, традиции, культы, табу, этические и моральные кодексы, а также социокультурный фон. Особенностями таких институтов является то, что они лишены жесткого автоматизма, не закреплены законодательно и представляют собой инструменты для гибкого регулирования поведением хозяйствующих субъектов в меняющихся условиях. Неформальные традиции являлись предметов исследования многих ученых. Так, Ф. Хайек пишет: «многие институты, составляющие фундамент человеческих свершений, возникли и функционируют без какого бы то ни было замысливше- 
го их и управляющего ими разума» [3]. А.Н. Пилипенко подчеркивает, что «...любое общество никогда не является заданной онтологической целостностью, а состоит из действий. Взаимосвязей отдельных индивидов, наделенных к тому же различной биологической и генетической наследственностью, различными психологическими особенностями и когнитивными способностями. В силу этого в обществе всегда наличествует сопротивление институциональным преобразованиям, связанное с различными ценностными представлениями индивидов, а не только с их экономическими интересами» [4].

Функционирование неформальных институтов не менее эффективна, чем работа формальных норм и правил. Ф. Хайек совершенно справедливо полагает, что «полезнейшие из человеческих институтов, от языка до морали и закона, вовсе не изобретены человеком сознательно...Основные инструменты цивилизации - язык, мораль и деньги - суть результат не проекта, а стихийного развития» [5]. Эндогенное происхождение этих институтов указывает на их желательность со стороны общества, так как они не навязаны сверху и учитывают ментальность и общность интересов населения государства. Живучесть, устойчивость во времени и пространстве таких институтов обусловлена тем, что субъекты воспринимают их как наиболее предпочтительными, по сравнению, например с формальными (экзогенными) институтами. Следует отметить, что поведение хозяйствующих субъектов, в том числе на рынке банковских услуг детерминировано влиянием как эндогенных, так и экзогенных институтов. Выше мы говорили об этом. Все больший интерес в этой связи вызывает такая категория как доверие, к которой у ученых нет до сих пор однозначного отношения, что связано с ее мультидисциплинарным характером, поскольку гносеологические корни данного явления уходят в психологию, социологию и другие гуманитарные науки. Тем не менее, все чаще специалисты в области экономики обращаются к изучению роли доверия в развитии социально-экономической системы. В последние годы сформировалась целая плеяда ученых, исследующих феномен доверия, среди них наиболее известны Ф. Фукуяма, М. Аглиетта, А. Орлеан, Я.Сергеенко, С. Важенин, В. Сухих, А. Ляско и многие другие. До сих в научном сообществе не прекращается дискуссия относительно дефиниции доверия. существует как минимум три представления о том, что же такое доверие:

во-первых, ряд ученых полагают, что это фактор социально-экономического развития [6]; во-вторых, что это один из основополагающих неформальных (эндогенных) институтов [7];

в-третьих, взгляд на доверие как квазиинститут неформального типа [8].

Последнее определение представляется нам наиболее корректным, поскольку в феномене доверия присутствует некая институционализация, то есть имеют место базовые свойства института, за исключением механизм инфорсмента (санкций, принуждения к исполнению нормы).

Таким образом, не вызывает сомнений тот факт, что доверие является необходимым элементом любой работоспособной системы, и. особенно, это касается финансово-банковского сегмента. Любая деятельность хозяйствующих агентов на рынке банковских услуг не может быть осуществлена при низком уровне институционального доверия к монетарным институтам, одним из которых является коммерческий банк. Источником такого доверия выступает соответствующее поведение контрагента, в данном случае института банка, который проявляет благожелательность по отношению к клиенту, заботиться о его капитале, предоставляя наилучшие способы его размещения и формирования, то есть реализует институциональные и экономические интересы [9] хозяйствующих субъектов. Следует отметить, что институциональное доверие к банку неразрывно связано с наличием доверительного отношения граждан к государству в целом, к денежной системе страны, к Банку России и другим финансовым институтам [10]. Доверие как психолого-социологическое явление весьма неустойчиво, то есть оно может как возрастать, так и падать. Естественно, что наиболее предпочтительным становится неуклонный рост институционального, межличностного, персонифицированного и деперсонифицированного доверия, поскольку его высокий уровень значительно снижает размер трансакционных издержек, сокращение случаев оппортунистического поведения, а, следовательно, увеличивает доходы акторов. Это обусловливает рост их благосостояния. В настоящий момент перед банковской системой стоит сложная задача повышения институциональ- 
ного доверия, рост которого сможет обеспечить коммерческим банком реализацию их экономических интересов, за счет привлечения значительного объема сбережений населения, а также кредитной экспансии в предпринимательский сектор.

Укоренение норм и механизмов поведения, восстанавливающих уровень доверия, можно рассматривать как необходимое условия эффективного функционирования банковской системы. Среди мероприятий, проводимых с целью роста доверия можно отметить, прежде всего, шаги по повышению транспарентности банковского сегмента, поскольку в первую очередь доверие к финансовым институтам подкрепляется соблюдением взятых на себя обязательств со стороны объектов денежно-кредитной сферы, отсутствием мошенничества, надежностью, компетентностью, добросовестностью, а также степенью информационной открытости. Еще одним направлением, реализация которого будет способствовать росту уровня персонифицированного доверия, является повышение финансовой грамотности населения. Недостаточный уровень осведомленности населения о финансовых продуктах не позволяет субъектам принимать взвешенные решения, предъявить значительный спрос на финансовые услуги, ко- торые некоторые граждане могут считать нецелесообразными и невыгодными.

Повышение финансовой грамотности может осуществляться при помощи трансляций в режиме реального времени, направленных на просвещение населения в различных сегментах банковской сферы, на разъяснение спорных моментов, ситуаций, на решение возникших проблем в финансовой сфере и т.д. Так, например, по данным ВЦИОМ, 77,2\% из числа не разбирающихся в банковских услугах респондентов не доверяют банкам, из осведомленных граждан доверяют банкам 64,8\% [11]. Уровень институционального доверия обусловливает готовность населения рисковать своими сбережениями: те, кто не доверяют банкам, предпочитают более низкие проценты по вкладам, но с большей надежностью, в отличие от доверяющих, готовых предоставить средства под более высокие проценты, но с большим уровнем риска.

Осуществление вышеназванных мероприятий позволит существенным образом повысить институциональное доверие, что обеспечит более эффективное функционирование и развитие банковской сферы, детерминируя реализацию ее институциональных и экономических интересов.

\section{Библиографический список}

1. Михайлов А.М., Белова Л.В. Формальные и неформальные институты в банковской сфере // Вопросы экономики и права. 2015. № 88. С. 48-52.

2. Boetteb P. Handbook on contemporary Austrian economics. Cheltenham: Edward Elgar. 2008. P. 335.

3. Хайек Ф.А. Право, законодательство и свобода: современное понимание либеральных принципов справедливости и политики. Москва. 2000. С.27.

4. Пилипенко А.Н. Факторы достижения институционального равновесия // Научные труды ДонНТУ. Серия: экономическая. 2009. Вып. 37-3. С.6.

5. Хайек Ф.А. Право, законодательство и свобода: современное понимание либеральных принципов справедливости и политики. М.: ИРИСЭН. 2000. С.28.

6. Важенин С., Сухих В. Доверие в российской торгово-промышленной среде XIX - XX веков // ЭКО. 2006. № 6. C. 168.

7. Белянин А, Зинченко В. Доверие в экономике и общественной жизни: монография. Москва. 2010. С.13.

8. Суриков К.Ю. Институциональное доверие и его роль в процессе развития денежно-кредитной сферы // Вестник Самарского государственного экономического университета. 2016. № 11 (145). С. 5-10.

9. Mikhailov A., Vishnever V., Konovalova M. Instituional regulation as a form of institutional interesis in the banking sektor // International Journal of Economic Perspectives. 2015. T. 9. № 2. C. 23-27

10. Суриков К.Ю., Коновалова М.Е. Особенности трансформации системы денежного обращения на современном этапе развития // Вестник Самарского государственного экономического университета. 2017. № 10 (156). С. 82-86.

11. Ибрагимова Д. О доверии населения финансовым институтам // Деньги и кредит. 2012. № 4. С.71. 